AREA: ECONOMIA Y FINANZAS

\title{
ON THE PROPERTY OF REAL OPTIONS AND THE ASSETS THAT GIVE RISE TO THEM
}

\author{
Jose Pablo Dapena Fernández \\ jd@cema.edu.ar \\ Universidad del CEMA
}

Abril de 2001

\section{Brief}

Property in financial options (derivatives) is stated and transferred through contracts, while in real options property may arise from assets under the management of the firm, without a formal contract properly defining property. Furthermore, in some situations the asset can be public, and its property shared among different agents or firms. The present paper intends to work on the mechanisms of appropriation (and hence transferability) of real options exploring the assets that give rise to them, and proposing the concept of indirect property of complementary assets. The meaning of property is explored, and also the dynamic of change between public and private assets. Finally, we develop on the features that define real options stemming from the indirect property of complementary assets.

Fields: D23, G00.

Keywords: Real options, property rights, intangible assets, indirect property. 
"... The church of Cienciology appealed to intellectual property rights to prevent publication and criticism of its texts by some people; pharmaceutical companies, claiming a patent over the human genome, are trying block scientific research, and the International Olympic Committee is trying to prevent non authorized covering of the following games. In fact, in the last Games the Committee banned letters from the participants to their relatives where they were commenting their experiences in the games,..."

- Extracted and translated from "Lo que el viento no se llevó" La Nación, April $28^{\text {th }} 2001$

\section{I - INTRODUCTION}

The literature on real options has developed significantly since the contributions of Dixit and Pindyck, Trigeorgis, Kulatilaka, etc. What it basically uses is the application of the methodology of valuation of financial options to value investments opportunities of the real world. In this context, waiting before committing a capital outlay can be assimilated to a call option, where the exercise price is the amount to be invested, the underlying security or asset is the value of the discounted cashflow generated by the project, there exists a period of time for the investment to be accomplished (maturity); and there is also a volatility associated to the casflow (given it is uncertain) and a riskfree interest rate.

Similarly, we can associate the right to invest in the future to grab new business opportunities if uncertainty unfolds favorably to the firm to a growth option or a call; on the other hand the firm always has an option to abandon any project and receive the liquidation value, without incurring additional losses, assimilating this option to a put ${ }^{\text {b }}$. However, whereas financial options are contractible, real options are not, in the sense that the rights do not arise from a contract but from possibilities open to the management of the firm stemming from the assets under management.

Introducing the concept of asset, we can broadly define it as a pack of possibilities of future consumption of goods and services. The agent tries to appropriate this packed consumption possibilities by exercising property rights on them. Every situation that allows the agent to get appropriation of this future consumption will be taken advantage of, either directly (by consuming the proceeds from the sale of the asset) or indirectly (by exchanging the asset for

\footnotetext{
${ }^{1}$ See references.
} 
goods and services). In this context, options are assets, and every right held by an agent or a firm is an option. The agent can exercise property on the rights, as the ones shown in the article that opens this work (intellectual property rights)

\section{How is the process of appropriation of assets that give rise to real options?}

The question becomes relevant for example in the following analysis: an entrepreneur starts up an investment project that allows her to expand to whole Latin America is things work out well, to the whole America and even Europe and the world if business develop positively for the project. From a real options analysis on it, it could be said that growth options open by the project are fantastic, given the possibilities of exercising them by further expansion abroad, so the value of the project would be greatly enhanced by valuing the calls associated with the prospects. This value will obviously be flawed, given that nothing guarantees the ownership of such options; unless the firm or the management has property rights arising from a patent on the product or services to be provided that legally limits the entry of new competitors, and hence expansion is feasible with some degree of certainty, the growth options will be available both for the entrepreneur and every other agent that replicates the product or service, so the possibilities will not be exclusive but shared with other potential entrants ${ }^{3}$. The difference between proprietary and shared investments will mainly come from the assets under management and the competitive advantages they can provide to the firm with respect to the competitors; in other words, ownership of assets under management will allow in case ownership of the real options associated. This approach is correct whenever the asset can be subject to legal ownership, but if we consider the human being as an asset for the firm, both for example in the role of human capital or as a loyal customer, the concept of ownership and property rights as we understand it starts to fade $\$$. We can therefore see the relevance of the question made above.

\footnotetext{
${ }^{2}$ For a simple description, see Dapena 2001.

${ }^{3}$ This point is touched by Trigeorgis (1997) but in his work he does not go further in the origins of property itself. See Trigeorgis (1997) pp-140-145.

${ }^{4}$ Given slavery is abolished.
} 


\section{II - A CONJECTURE ON PROPERTY}

We can define (in a rough sense) two categories of property rights: legal and economic. The economic property right acquired over an asset is right the owner has to consume either directly or indirectly (through exchange) the residual product of the asset. The legal rights will be those the legal system grants as private ownership. We may find cases where these two concepts do not match themselves. In primitive societies, the "legal right" may come from the use of force, hence the "legal" owner is not always the one for whom the asset is worth the most. Evolution of civilization makes society to organize itself through a set of laws and norms of general knowledge and approval, where property rights start to be respected, given that law reduces the risk of compulsive expropriation.

Given that real options represent rights not always stemming from contracts signed by parts, but from possibilities open to the management given the assets the firm has under its administration, it becomes relevant to inquire about the general process through which assets are appropriated and exclusiveness is kept. Assets, as possibilities of direct or indirect consumption are subject to risk given that realizations of the casflows are not certain ${ }^{\mathrm{G}}$, and hence to maximize the opportunity set of consumption they provide, it can be thought that from an economic (or efficiency) point of view, the asset should be under the ownership of the agents in better position to influence and manage these two attribute:

- the flow of possibilities of consumption they give rise to, arising from access to the residual income or product.

- the risk associated to the flow of possibilities of consumption

From free supply and demand and access to well developed capital markets with no relevant transactions costs, and provided that transfer of ownership of assets is not forbidden, property

\footnotetext{
${ }^{5}$ The production and hence consumption possibilities arising from owning an asset can either certain (the level of consumption possibilities remains constant independently of the state of the nature) or random (possibilities are contingent on the state of the nature).

${ }^{6}$ In this sense the agent solves the problem of maximizing the expected consumption level subject to a risk level, or alternatively, minimizing the risk associated to the flow of possibilities given an expected level of

consumption. The origin of this problem comes from the theory of finance, where the agent solves a similar
} 
of them should end up on the hands of agents in better conditions to manage the two features mentioned before. The allocation among agents of the income of the assets (in terms of consumption possibilities) and the variability of these consumption possibilities $\square_{\text {determines }}$ to what extent the rights are well delimitated, and the function governing property could be defined by the capacity by the owner of assuming responsibility for the product of the asset and its variability. We shall say that property rights are well defined when their holder receives full impact from the use of them.

Knowing that in some situations the consumption possibilities associated to an asset may vary contingent on the state of the nature, and knowing that the owner of the asset is the residual claimant of its proceeds, we introduce the concept of robustness into the analysis of property rights. We shall say that property rights are robust if ownership of the asset remains with the agent independently of states of the nature (so that the risk of expropriation is minimal or even null) unless the agent decides voluntarily to alienate the asset in certain states of the nature; on the other hand if ownership is variable on the state of the nature and there is a high risk of expropriation, we shall say property rights are weak. There will be hence assets for whom property rights are more robust, and others for whom they are weaker. The different states of the nature may affect the consumption possibilities associated to the asset in an idiosyncratic way (specifically for that asset or group of assets) or systematic (for all assets in the economy at the same time).

We can also associate robustness to the dynamics of time; we can define property in a static sense (for a given time) or in dynamic sense (across time), so in many cases we will say that property is absolute at a specific point of time, but may be relative in different points of time (risks of expropriation in the future). This situation means that property rights are to be defined robust in a dimension of time as well.

The concepts just described are closely linked to a legal approach of property right. As we already saw, there is an economic dimension of property rights, which might be different from legal ownership. Following this concept and as it was mentioned before, we can propose that the natural owner of an asset is the person who is in best situation to manage the consumption

problem for optimizing the quantities of each asset in an optima portfoli (see any primer in finance, e.g. Brealy and Myers).

${ }^{7}$ For further discussion on the allocation of variability, see Barzel 1997, pp 77-84. 
possibilities arising from the asset and its variability, maximizing the first while minimizing the second. This proposition becomes relevant from the point of view of the possibility of alienating the assets. For, if assets are subject to alienation in the sense that property is transferable among agents, ownership will finally (assuming market exists) end up on the agent who is willing to pay the most for the asset, given that she is able to extract the most of it and better handles the variability associated to the consumption possibilities. In the article that opens this paper we can observe the organizers of the Olympic Games sell the exclusiveness of them, showing there is a part which is in better position to exploit this asset (and the rights associated).

\section{II.A- DYNAMIC OF CHANGE BETWEEN PUBLIC AND PRIVATE ASSETS}

Nature is composed of goods that give rise either directly or indirectly to possibilities of consumption. These goods can be public or private. Public goods are those available for consumption of everyone, and consumption by one agent does not reduce the possibilities of consumption of another.

Png $(1998)^{8}$ proposes that the difference between a public and a private asset (Png defines goods instead of assets) will arise from the concept of congestionability. As long as different agents want to make use of the asset at the same time and they do not affect themselves reciprocally on their use (in other words, the use by one does not affect the use another one wants for the asset), the asset will be public and can be obtained freely ${ }^{9}$. However, if many other people want to use the asset, and its stock is given, there will be a point where the use by one agents affects the use by another, giving place to congestion in the use. We can assert that at this point the asset starts to transform from public to private, where agents compete to its appropriation and are willing to pay a positive price for it.

The dynamics of availability of goods, technology and changes in the structure of preferences give rise to situations in which assets originally public become scarce (for example because evolution of technology makes access to the asset much easier), and property rights start to be

\footnotetext{
${ }^{8}$ See pp 392-395.
} 
important; if they are not well defined (or imperfectly defined) as one would expect from an originally public asset, competition would arise. As the asset evolves into private, its price starts to rise, and agents compete to establish property rights on it, defining them in a more accurate way . On the other hand, for the same reasons, there will be assets originally private that are left to the public domain, given that the set of possibilities of consumption associated to them is null (like garbage); their represent assets that agents or firms have decide not to claim.

When the value of the asset rises, every one of the partial owners and possibly new ones will compete to capture part of that increment. If property rights are imperfectly (or not well) defined, disputes emerge over the distribution of the increment in value.

This dynamic of change between public and private assets is present in the discussion that motivates this paper. The assets giving rise to real options can be either private or public, being the second case the interesting one, given that the asset has value but it is not subject to direct appropriation. In the article above we can observe that the public image of a persona or the letters she writes cab be of not value initially (be public), but when public attention (and the way it is monetized from advertising) is placed on it, there will be an interest in stating property rights on it.

\section{II.B - PROPERTY RIGHTS FROM RESIDUAL CONTROL AND EXCLUSIVENESS OF USE}

As it was mentioned in the previous section, one attribute of ownership is the access by the owner of the asset to the residual income or product ${ }^{1}$ generated by it, but considering only this attribute will make our analysis be incomplete. The owner of an asset has also the right to decide the final use of an it, being this attribute a relevant feature of property rights. Grossman y Hart (1986) point out in the context of a firm that residual control is of much

\footnotetext{
${ }^{9}$ Public goods have not property rights attached to them, because of their nature, and hence their have no price. Private goods have property rights on them, being owned by agents or firms.

${ }^{10}$ This section uses concepts from Barzel 1997, pp 16-32, for further discussion see the author.

${ }^{11}$ Previously labeled consumption possibilities
} 
importance when it has to decide whether to buy a good or a service or produce it internally; this dilemma arises from the natural incompleteness of contracts 12 .

The owner of an asset can delegate by contract rights of use to another agent, but she keeps all the rights of use not specifically written in the contract. This observation can be used to complement the concept of property derived previously; we can say that property gives rise also to residual rights of control over the use of the asset ${ }^{1 .}$. As long as an agent can fully decide on the destiny and use of the asset, she will be making use of the attribute of ownership. These concepts become relevant in our frame given that when an agent can allow or impede particular uses of the asset is acting as if she was its owner. In the article, the organizers of the Olympic Games prevent the participant to make public aspects related with the games.

We see from this exposition that control of use derives in possibility of exclusion. The concept of exclusiveness complements the dynamics of change between public and private assets; an asset may become private by means of exclusiveness. The right to decide on the use of an asset implies that the owner is in conditions to exclude some users or consumers form the use of the asse 1 . If an asset is valuable for a certain group of consumers or users, and a potential owner is not able to exclude them from their use, therefore she will not be able to state full property rights on the asset, and the asset will not be subject to alienation and transferability. Even though the asset may be of high value, the agent cannot state and transfer ownership provided that no one would pay for an asset of free use and access $\frac{15}{15}$. This concept

\footnotetext{
${ }^{12}$ In this section we shall describe the reasons for which property rights are important, comparing with situations in which the asset can be rented. A complete contract rules out any kind of opportunistic behavior (for further discussion see Bezanko et al 1996). All possible contingencies and actions associated to them are mapped out, limiting discretional behavior. However, in the real world such a contract is impossible to write, given that there will exist contingencies not contemplated originally in the contract arising from the complexity of the future. A contract is incomplete because do not take into account some contingencies arising from:

Limited rationality: it is impossible for the human mind to consider all possible contingencies. Difficult to state metrics: it may be difficult to specify what means fulfillment of the contract.

Asymmetric information: the parts may not have the same information regarding the future and may leave some contingencies without specification in purpose.

If contracts were complete, it would not mind who is the owner of the asset. The contract would specify in detail what actions are to be taken at each time (like a computer program) and the decision of owning or renting would be irrelevant. Given this is not possible and contract are incomplete, it becomes relevant the residual control of use for deciding when facing contingencies not previously written.

${ }^{13}$ The is no necessarily a one to one relationship between residual income and residual control. However, to rule out inefficiencies, it would be more efficient such a correspondence.

${ }^{14}$ See Png (1998) pp 396-401) for better explanation.

${ }^{15}$ We can automatically think of the "free raider" concept.
} 
is of much importance to ensure there is a possibility of making a transaction given full ownership over an asset.

\section{III - INDIRECT PROPERTY RIGHTS AND REAL OPTIONS}

As we saw previously, we can fully exercise property rights on assets as long as exclusiveness of use is guaranteed. One way to guarantee exclusiveness of use is by acquiring legal property rights through the legal system. There will be assets over which legal, formal or direct ownership can be established, and there will be others (like some intangibles or human capital) over which it would not be possible to establish it. We see it may not be possible to establish legal property rights on the public image of a person, or the comments she makes to the press, though it may attract media attention and hence becomes valuable $\sqrt{16}$. However, from an economic point of view there will be situations where these assets are complements to others and they derive much of their value from this relation (a football player as part of a club, a lawyer as part of a well recognized buffet); it may be the case these complementary assets are of such a kind that is possible to establish legal ownership over them, like the stadium where the competition takes place, the brand of a firm, etc., prompting hence exclusiveness of access and use can be guaranteed.

Legal property over certain assets gives rise to indirect property of others assets not available to direct appropriation, as long as these assets are complementary of the first assets and exclusiveness of use can be warranted.

The proposition holds true for any kind of asset, however we find it particularly relevant for assets giving rise to real options. This proposition introduces a relevant point in our discussion, which is given by the attribute of complementary of two asset to provide a flow of possibilities of consumption greater than the flow arising from the two separate. This idea of

\footnotetext{
${ }^{16}$ Taking human capital as an example, each agent is the owner of her human capital, and this property cannot be transferred from a legal point of view.
} 
complementary assets ${ }^{10}$ gives rise to what we will propose as indirect property rights over them. This category of rights allow agents set property rights over public assets, over which legal or direct property rights cannot be deployed, given that their derive most of their value from the joint use with other assets over which legal or direct property rights can be set, so the indirect property will come from complementary assets.

In our analysis we have been talking about assets, without trying to mention categories of them available to the firm. An accounting version of assets comes from inspecting the left hand side of a balance sheet:

\section{- Working assets and fixed assets}

- Cash, bank accounts and securities

- Receivables

- Inventories

- Fixed assets (real estate, buildings, machinery, etc.)

- Goodwill and others long term assets

It becomes somehow obvious that legal property can be established over these categories of assets. However, it has to be recognized that the following categories of assets are of much importance as means of providing services or producing goods 18 .

\section{- Human Capital}

- Know -how

- Education

- Attitude

- Work experience

- Skills related to the job

\footnotetext{
${ }^{17}$ Suggested by Grossman y Hart 1986. Take for example the case of a firm and its employees; the human capital is more valuable to the employees complemented with the assets the firm owns. In this sense we can say there is a shared ownership of the human capital through complementary assets, even though the forma owner is the employee from a legal point of view. Control over non human assets may give rise to control over human assets.
} 
- Entrepreneurship motivation

- Capacity of innovation

- Resilience

\section{- Relational Capital}

- Brand

- Portfolio of customers

- Loyalty of clients

- Distribution channels

- Intercompanies relations of business

- Agreements on use of licenses

- Franchises

\section{- Structural Capital}

\section{Intellectual property}

- Patents

- Copyrights

- Rights of design

- Trademarks

\section{Infrastructure assets}

- Management philosophy

- Corporate culture

- Business processes

- Information systems

- Network systems

- Financial relationships

${ }^{18}$ The categories of assets draws from Dzinkowski (2000). 
One of the features of some of theses assets is that they may give rise to real options. Take for example "Loyalty of clients"; as long as a client is satisfied and hence loyal to the product or service, the firm is able to exercise cross selling of product and services, giving rise to the existence of a growth option. Similarly, consider the asset "Brand"; if the firm has a well recognized brand, it allows the firm to expand to different markets with its business proposal, allowing the firm to open subsidiaries and scaling up the business, by itself or through franchises. Knowing from the previous section that it is not so simple to establish property rights over these assets because of legal or technical matters, we can search for complementary assets in a way to establish legal or direct ownership over them and by extension indirect property rights over the real options stemming from complementary assets (and hence transferability of these options).

Now we will show this proposition in a more formal exposure. Let assume we have a set $\mathrm{H}$ of assets like the ones exposed before:

$$
\mathrm{H}=\{\mathrm{A}, \mathrm{B}, \mathrm{C}, \mathrm{D}, . .\}
$$

being all (potentially 19 ) these assets under the administration of the firm. Lets also assume there is a function $\mathrm{V}$ that takes these assets as inputs and maps them into value (in terms of consumption possibilities), and whose level will depend upon particular combinations of assets given by subset $\mathrm{H}_{\mathrm{i}}$

$$
\mathrm{V}\left(\mathrm{H}_{\mathrm{i}}\right)
$$

where a greater $\mathrm{V}$ allows greater consumption possibilities for the owner, so better is preferred to less (we can include a utility function increasing on $\mathrm{V}$ that satisfies this requirement, where $\mathrm{V}$ is associated to consumption); so:

$$
\mathrm{V}_{\mathrm{a}} \text { is preferred to } \mathrm{V}_{\mathrm{b}} \text { if } \mathrm{V}_{\mathrm{a}}>\mathrm{V}_{\mathrm{b}}
$$

\footnotetext{
${ }^{19}$ It means the whole set available for use by the firm, where it chooses those that better fit its business model.
} 
In this context, assume firm $\mathrm{X}$ has under its management the asset $\mathrm{A}$, and can also acquire the asset B (both legally subject to appropriation) where

$$
\mathrm{H}_{\mathrm{x}}=\{\mathrm{A}, \mathrm{B}\}
$$

but:

$$
\mathrm{V}_{\mathrm{x}}(\mathrm{A}) \geq \mathrm{V}_{\mathrm{x}}(\mathrm{A}, \mathrm{B})
$$

so acquisition of B will not be convenient from an economic point of view (or at least the firm will be indifferent). Assume there exists an asset $\mathrm{C}$ which gives rise to a real option (for example an asset like customers that gives rise to growth options). Asset $\mathrm{C}$ is not directly subject to appropriation, in other words its use or product is open to any firm Y, Z, W, etc., but we observe that between assets $\mathrm{B}$ and $\mathrm{C}$ there is a relation of complements of the following form:

$$
\mathrm{C}=\mathrm{kB}
$$

where $\mathrm{k}$ is the coefficient of this relationship, stemming from technological advances or changes in preferences (for example new bundles of products), and as a consequence of the changing nature of technology or preferences, the firms are not initially aware of this relation. Firm $\mathrm{X}$ observes it and tries to exploit it in its benefits, so assume that the value of the real option stemming from $\mathrm{C}$ is

$$
\mathrm{V}_{\mathrm{x}}(\mathrm{A})<\mathrm{V}_{\mathrm{x}}(\mathrm{A}, \mathrm{C})
$$

and

$$
\mathrm{V}_{\mathrm{x}}(\mathrm{A})<\mathrm{V}_{\mathrm{x}}(\mathrm{A}, \mathrm{B}, \mathrm{C})
$$


were we can infer that firm $X$ derives a benefit from acquiring $C$ through $B$, even when the acquisition of $\mathrm{B}$ causes a loss by itself, provided that the increase in value from $\mathrm{C}$ outweighs this individual loss. However, if $\mathrm{C}$ is public and consequently open to the use of other firms, and firm $\mathrm{X}$ tries to appropriate it, it will logically be followed by imitation by the rest of the firms, and hence the effect of this shared use by $\mathrm{X}$ on $\mathrm{V}_{\mathrm{x}}$ will be almost fully diluted; if we think $\mathrm{n}$ firms uses $\mathrm{C}$ symmetrically and the impact is the same for all of them, the increase in value for $\mathrm{X}$ will be

$$
\mathrm{V}_{\mathrm{x}}(\mathrm{A})<\mathrm{V}_{\mathrm{x}}(\mathrm{A}, \mathrm{C} / \mathrm{n})
$$

where $n$ represents the number of firms actively using asset $C$, and $C / n$ is the shared use by any firm of asset $\mathrm{C}$. Under this situation, given that $\mathrm{X}$ cannot exclude other firms from the use of asset $\mathrm{C}$, it would never pay to acquire the asset $\mathrm{C}$ the full increase value $\mathrm{P}$

$$
P=V_{x}(A, C)-V_{x}(A)
$$

for something worth

$$
P_{n}=V_{x}(A, C / n)-V_{x}(A)
$$

given the shared use by other firms. But as we say, if firm $X$ notices first the relation of complements between assets B and $\mathrm{C}$, and it can find a way to acquire and establish legal or direct property rights over $\mathrm{B}$, this strategy will allow it to exercise indirect ownership over $\mathrm{C}$ through the relation $\mathrm{k}$. Under this mechanism, property over B (legal or direct) can derive a certain degree of exclusiveness in the use of $\mathrm{C}$ given its complement $\mathrm{B}$, which allows firm $\mathrm{X}$ to increase its function $\mathrm{V}$ above the price $\mathrm{P}_{\mathrm{n}}$, so that appropriation of the real option becomes profitable,

$$
\mathrm{V}_{\mathrm{x}}(\mathrm{A}, \mathrm{B}, \mathrm{C})>\mathrm{V}_{\mathrm{x}}(\mathrm{A})
$$


by excluding potential user of asset C. Some key points of this analysis are the nature of complements between $\mathrm{C}$ and $\mathrm{B}$, the legal property that can be established over $\mathrm{B}$, the possibility of excluding access to $\mathrm{C}$ from other users, and the fact that changes in technology and preferences give rise to new relations of complements between assets. As long as property rights over B guarantees exclusion 20 of other users of asset $\mathrm{C}$, there will be room for the monetization of the real option under indirect property rights.

These indirect property rights will have the same attributes of relevance and follow the same process of formation of property rights mentioned before. Under the mechanism proposed, these originally public assets can be subject to alienation, and hence transferability through residual control over complementary assets (e.g. if we want to sell C, we are able to sell B and therefore the new owner will be capture the proceeds from $\mathrm{C}$ ). This analysis allows us to explain the following situations:

- It explains for example how the right to take photographs in a wedding can be sold to a magazine, just by controlling the building where the wedding takes place, which, being private, gives the owner the right to exclude other people from entering.

- It allows us to explain how the TV futbol rights can be sold by futbol federations and organizers by controlling the stadiums where each match takes place, and excluding access to TV cameras not authorized.

- In a similar way, it allows us to explain how comments made by participants in the Olympic games can be banned, just by signing a clause where participation in the games makes the participants be subject to rules regarding public comments, and in case they do not agree they are not allowed to participate in the event.

- Analyzing the case of cable companies, health companies, etc., then we observe that most of the value of these firms derives from the portfolio of customers they

\footnotetext{
${ }^{20}$ This exclusion can be either physical or technological.
} 
have $\mathrm{be}^{2}$, yet they are not owners of the customers, they just own the assets needed to provide services to them, and keep them linked to the firms. In this case the asset $\mathrm{C}$ will be the portfolio of customers, and asset B will represent those assets deployed to guarantee services to the customers.

\section{IV - CONCLUSIONS}

The description made before allows us to answer the question raised initially. Options represents rights, and real options represent rights over investments made in the real economy. In the case where the assets which give rise to real options are not subject to legal or direct ownership (because there are not explicit rights defined or they are initially public), the agent may be able to establish indirect property rights by owning complementary assets over which direct ownership can be set and defined. We have seen those situations under which property rights are relevant, the attributes that they give rise to, the dynamics of change between public and private assets, property in terms of residual rights of control which allows to exclude other participants from the use of assets, and hence allows for their full monetization. The mechanism of indirect property recreates the attributes of ownership and most of it, recreates exclusiveness of use for those assets not subject to direct ownership, by means of using complementary assets. A relevant point to be made comes from the dynamics of change between public and private assets and the creation of new relation between assets due to developments in technology, situation that may make valuable some assets that were initially public and worthless, prompting the need for a clear definition of the ownership over them where property rights becomes more relevant using mechanisms like the one proposed herein.

Most of traditional assets are now commodities, and assets owned by people (like human capital, brand recognition, expertise, loyalty) are every day more important and relevant for making a difference in value, giving rise to real options.

\footnotetext{
${ }^{21}$ In fact, when such companies are valued, the value sometimes comes from attaching and individual value to the customer and then multiplying this individual value by the quantity of customers in the portfolio, as a proxy for the true value.
} 
A portfolio of loyal customers allow the firm to establish ownership over their associated growth options by exercising cross-selling with minimum investments; changes in business models are much easier for the firm that counts with high quality human capital, requiring little training and providing flexibility to the firm 22 .

In both cases direct ownership will not be attainable, so the correct mechanism act as if the asset was owned by the firm will come through the use of complementary assets.

\footnotetext{
${ }^{22}$ A stock options plan intends to keep human capital linked to the company, using the control the firm has over its shares.
} 


\section{References}

Barzel Y., Economic Analysis of Property Rights, 1997. Cambridge University Press. Second Ed.

Bezanko D., Dranove D. y Shanley M., Economic of Strategy, 1996. John Wiley and Sons.

Dapena, J. 2001. Flexibilidad, Activos Estratégicos, y Valuación por Opciones Reales. Documento de trabajo 187. Universidad del CEMA.

Dixit A. and Pindyck R. S., Investment under Uncertainty, Princeton University Press, Princeton, N.J., 1994.

Dsinkowski R. (2000), 'The measurement and management of intellectual capital: an introduction". Management Accounting 78, no. 2:32-36

Grossman S. y Hart O. 1986, "The Costs and Benefits of Ownership: A Theory of Vertical and Lateral Integration". Journal of Political Economy Vol. 94 no. 41.

Hart O., Firms, Contracts and Financial Structure. 1997. Clarendon Lectures in Economics. Oxford University Press.

Kulatilaka N. and Marcus A. (1992), "Project valuation under Uncertainty: when does DCF fail? ". Journal of Applied Corporate Finance 5, no. 3: 92-100

Png I., Managerial Economics. 1998. Blackwell Publishers.

Trigeorgis L., Real Options: Managerial Flexibility and Strategy in Resource Allocation, The MIT Press, Cambridge Massachussets, 1997

Trigeorgis L. (1988), "A Conceptual Options Framework for Capital Budgeting". Advances in Futures and Options Research 3:145-167. 